\title{
Saúde, migração e direitos humanos
}

\author{
Natália Ramos*
}

\section{Resumo}

Os fluxos migratórios são hoje mais numerosos, mais rápidos, mais diversificados e complexos do que no passado, atingindo todos os continentes, géneros, classes sociais, gerações e os vários domínios da vida pública. As questões da saúde, da qualidade de vida, dos direitos humanos e da cidadania das populações migrantes estão no centro das preocupações dos países da União Europeia, nomeadamente Portugal, dos profissionais e dos investigadores. O acesso à saúde é um direito fundamental indispensável para o exercício dos outros direitos humanos. A presente comunicação analisa as múltiplas e complexas relações e variáveis individuais e colectivas, nomeadamente psicológicas, sociais, culturais, ambientais e políticas, implicadas nas questões da saúde e da doença, na acessibilidade aos serviços de saúde e, ainda, no processo migratório e de aculturação. Estas variáveis podem originar isolamento, stresse, ansiedade, depressão, conflito, exclusão e doença, elementos que poderão afectar não apenas a saúde mental e física, o bem-estar e a qualidade de vida dos homens e das mulheres migrantes, como dificultar, igualmente, o seu acesso aos cuidados de saúde e à prevenção, a reivindicação dos seus direitos e o exercício de cidadania.

Palavras-chave: Saúde; Migração humana; Direitos Humanos; Cidadania; Interculturalidade.

\section{Health, migration and human rights}

\begin{abstract}
The migratory flows are today more numerous, faster, more diversified and complex than in the past, reaching all continents, genders, social classes, generations and several domains of public life. Health, quality of life, and human rights matters, as well as the citizenship of migrant populations, are the heart of concerns of many countries of the European Union, namely Portugal, and of professionals and researchers. The access to health care is a fundamental indispensable right to the exercise of other human rights. The present communication analyses the multiple and complex relations and individual and collective variables, namely psychological, social, cultural, environmental, and political variables, implied in the health and illness matters, in the access to health care services, as well as in the migratory and acculturation processes. These variables may cause isolation, stress, anxiety, depression, conflict, exclusion, and illness, elements that may affect not only mental and physical health, but also the well-being and quality of life of migrant men and women, and may also hinder their access to health care and prevention, their claim to their rights, and the exercise of their citizenship.
\end{abstract}

Keywords: Health; Human migration; Human rights; Citizenship; Transcultural matters.

\footnotetext{
* Professora Associada da Universidade Aberta, Lisboa; Investigadora do Centro de Estudos das Migrações e das Relações Interculturais (CEMRI), onde coordena o grupo de investigação: Saúde, Cultura e Desenvolvimento; Directora/Coordenadora do Mestrado em Comunicação em Saúde da Univ. Aberta; Doutorada em Psicologia, especialidade Psicologia Clínica Intercultural, pela Universidade de Paris V, Sorbonne. Universidade Aberta, Rua da Escola Politécnica,147 1269-001 Lisboa; Telef. 213916300; Email: natalia@univ-ab.pt
} 


\section{Salud, migración y derechos humanos}

\section{Resumen}

Los flujos migratorios hoy día son más numerosos, más rápidos, más diversificados y más complejos que en el pasado, llegando a todos los continentes, géneros, clases sociales, generaciones y los distintos sectores de la vida pública. Las cuestiones de salud, de cualidad de vida, de los derechos humanos y de la ciudadanía de las populaciones inmigrantes están en el centro de las preocupaciones de los países de la Unión Europea, especialmente Portugal, entre los profesionales y los investigadores. El acceso a la salud es un derecho fundamental indispensable para el ejercicio de los otros derechos humanos. La presente comunicación analiza las múltiplas y complejas relaciones y variables individuales y colectivas, es decir las psicológicas, sociales, culturales, ambientales y políticas, involucradas en las cuestiones de salud y de la enfermedad, en la accesibilidad a los servicios de salud e incluso el proceso inmigratorio y de aculturación. Estas variables pueden dar origen al estrés, a la ansiedad, depresión, conflicto, exclusión y enfermedad, elementos que podrán afectar no solamente la salud mental y física, el bienestar y la cualidad de vida de los hombres y mujeres inmigrantes, sino dificultar también su acceso a los cuidados de la salud, a la prevención, a la reivindicación de sus derechos y al ejercicio de la ciudadanía.

Palabras-clave: Salud, migración humana, derechos humanos, ciudadanía, interculturalidad.

\section{Introdução - Indicadores e Dinâmicas Interculturais}

No mundo contemporâneo, as novas realidades multi/interculturais fazem com que os homens e as mulheres do século XXI, mantenham múltiplas pertenças identitárias e redes transnacionais, conheçam novas oportunidades de desenvolvimento, desenvolvam novas formas de relações sociais e interculturais e novas práticas de cidadania, tenham conquistado novos direitos mas conheçam, igualmente, novos conflitos e problemas sociais, comunicacionais e de saúde e novas formas de discriminação e de exclusão.

As sociedades actuais são confrontadas por um número crescente de populações estrangeiras, originárias de diferentes culturas e portadoras de costumes e línguas específicas, que afluem, sobretudo às cidades e que partilham espaços, actividades e o quotidiano.

Tanto a globalização e a mobilidade das populações, como a urbanização, aumentaram sem precedentes os contactos entre as culturas e a coabitação entre diferentes grupos étnico-culturais e modos de vida contribuindo, assim, para a multi/interculturalidade das sociedades, particularmente das cidades e colocando sérios desafios à gestão da diversidade cultural, à comunicação intercultural, às políticas públicas nos diferentes sectores e aos Estados.

O crescente desfasamento entre níveis de desenvolvimento de regiões e países e entre estruturas demográficas de países ricos e de países pobres, os conflitos armados e políticos, têm originado um número cada vez maior de migrantes e de refugiados.

No mundo globalizado e aberto de hoje, os indivíduos continuam a migrar, para dentro ou para fora dos seus territórios, em busca de melhores perspectivas e condições de vida. Estas deslocações estão em aumento crescente e deverão ser consideradas como um direito humano, tal como é consagrado no artigo $13^{\circ}$ da Declaração Universal dos Direitos Humanos, adoptada em 1948 pela Organização das Nações Unidas (ONU): Todo o indivíduo tem o direito de circular livremente e escolher a sua residência no interior de um Estado. Todo o indivíduo tem o direito de abandonar o país em que se encontra, incluindo o seu, e o direito de regressar ao seu país.

As migrações ocorrem, sobretudo, no interior dos países, estimando-se que haja aproximadamente 740 milhões de migrantes internos e 200 milhões de homens e mulheres migrantes internacionais. Os que migram devido à insegurança, catástrofes ou guerra são cerca de 14 milhões e representam 7\% dos migrantes no mundo (ONU).

Os fluxos migratórios têm vindo a aumentar, atingindo todos os continentes. É a Europa que acolhe um maior número de migrantes (64 milhões), seguida da Ásia (53 milhões) e da América do Norte (44,5 milhões). O número de migrantes internacionais quase triplicou, desde 1970. Só na União Europeia (UE), o número de migrantes provenientes de países extra europeus aumentou $75 \%$, desde 1980 .

Estes fluxos migratórios crescem a um ritmo mais rápido do que o crescimento da população mundial, verificando-se uma feminização das migrações. Com efeito, cerca de 100 milhões de migrantes internacionais são mulheres, predominando as migrações familiares nos fluxos migratórios de carácter permanente. É de salientar que a reunificação familiar é a principal via de entrada da imigração para a União Europeia, verificando-se que 
$75 \%$ dos fluxos migratórios anuais são constituídos por cônjuges, filhos e outros familiares. Segundo a Organização para a Cooperação e Desenvolvimento Económico (OCDE, 2007), as migrações familiares atingem $70 \%$ nos EUA e constituem um terço das migrações permanentes no Japão e no Reino Unido. Estes fluxos têm vindo a aumentar atingindo todos os continentes e os diferentes sectores da vida pública, prevendo-se que em 2050 as migrações internacionais atinjam os 230 milhões.

Nos países da OCDE os fluxos de estudantes estrangeiros, também aumentaram mais de $40 \%$ desde 2000 , assim como, os fluxos de trabalhadores qualificados. A título de exemplo, em 2000, 11\% dos enfermeiros e 18\% dos médicos que trabalhavam nos países da OCDE eram de origem estrangeira (OCDE, 2007)

No que diz respeito a Portugal, país tradicional de emigração, estimando-se que o número de portugueses e de descendentes no estrangeiro é de perto de 5 milhões, este tem vindo, igualmente, a reforçar o seu carácter de país de imigração. A partir sobretudo dos anos 70, Portugal viu-se confrontado com o fenómeno da imigração, a população imigrante em Portugal representando em 2007 perto de $5 \%$ da população residente (435.000 estrangeiros), (SEF, 2007), concentrada nas principais cidades: Lisboa, Faro, Setúbal, Porto, Aveiro, Coimbra e Braga. A comunidade estrangeira mais numerosa em Portugal é a brasileira (66.354) seguida das seguintes comunidades: cabo-verdiana (63.925); ucraniana (39.480); angolana (32.728); guineense (23.733); do Reino Unido (23.608) romena (19.155); espanhola (18.030); moldava (14.053).

Em 2007 segundo dados do Instituto Nacional de Estatística - INE (2008), nasceram em Portugal 9.887 crianças de mães estrangeiras, perfazendo $9,6 \%$ da totalidade dos nascimentos neste ano. Se tivermos em conta os bebés nascidos de pai estrangeiro, a percentagem é de $11,8 \%$ neste mesmo ano. São os brasileiros o grupo de estrangeiros que contribuem com o maior número de crianças e que se mantém em primeiro lugar na união com portugueses. Os dados do INE registam, igualmente um aumento de casamentos mistos em Portugal, ou seja, entre portugueses e estrangeiros. Entre 2005 e 2006 os casamentos com estrangeiros aumentaram de 1.364 para 5.696. Em 2007 dos 46.329 casamentos celebrados, 12,3\% foram entre portugueses e estrangeiros. Analisando por sexo, destacam-se os casamentos de homens portugueses com mulheres estrangeiras ( $8,4 \%$ do total). Os casamentos entre brasileiros e portugueses aumentaram perto de $50 \%$ entre 2005 e 2006, tendo-se registado só em 2006, 2.917 uniões.
É a cidade onde reside actualmente mais de metade da população mundial $(65 \%)$ que acolhe um número cada vez maior de migrantes. Esta é, e será, cada vez, mais espaço de pluralismo cultural, tendo a cidade de "promover e respeitar as esperanças e os medos dos seus cidadãos"(Rykwert, 1988) e responder às suas necessidades e aspirações. A gestão da diversidade cultural nas zonas urbanas constitui uma das grandes preocupações do Conselho da Europa e da Comissão Europeia, os quais projectaram para 2008 o programa designado "Cidades Interculturais" insistindo em que é necessário promover a "Cidade Aberta", de modo a fazer-se da cidade um espaço plural, um lugar privilegiado de diálogo intercultural, de concretização de direitos, de cidadania e de qualidade de vida.

Prevê-se que em 2030, as cidades do mundo em desenvolvimento acolham $80 \%$ do total da população urbana. A preocupação pela inclusão, bem-estar e qualidade de vida nas cidades está presente em vários organismos internacionais, tais como a UNESCO, o Conselho da Europa, a Comissão Europeia e a Organização Mundial de Saúde, (WHO (1996).

Ao nível da saúde surgiu em 1985 a expressão “Cidades Saudáveis", tendo a OMS lançado em 1988 o movimento das Cidades Saudáveis (WHO/EURO/HCPO (1988), a que já aderiram na Europa perto de 1300 cidades (Lafond, Heritage, Farrington, \& Tsouros, 2003).

Para estes organismos as autoridades públicas e os actores sociais, deverão promover a comunicação intercultural nas instituições, nos espaços físicos e na organização da vida cívica de forma a impedir o desenvolvimento de ghettos religiosos e étnico-culturais e a promover políticas e espaços onde os indivíduos se possam encontrar, partilhar costumes culturais e religiosos e exercer os seus direitos.

A diversidade cultural poderá sustentar o reconhecimento positivo da diferença, do Outro mas poderá, também, servir de suporte para acentuar as diferenças entre as maiorias e minorias e desencadear atitudes de discriminação, racismo e exclusão. A cidade, enquanto espaço social e simbólico, espaço de pluralismo cultural e de diferença, é cenário onde se formam, afirmam e reestruturam identidades, onde se reinventam no quotidiano práticas sociais e de saúde, relações interculturais e diferentes modalidades de participação e cidadania. É também espaço onde se exprimem, tensões, conflitos, violência, doença e exclusão. Em relação ao espaço social nós somos, também o espaço que habitámos, já que o contexto espacial influencia atitudes, comportamentos, expectativas, realizações, dinâmicas sociais e identitárias. 
As necessidades individuais, as realizações e projectos de vida, o desempenho pessoal e profissional, a saúde, estão estreitamente relacionados aos ambientes e redes sociais de vivência urbana, aos contextos sociais, culturais, económicos e políticos em que os indivíduos vivem e trabalham (Kleit, 2001).

As cidades são hoje e serão, cada vez mais, espaços multiculturais, por excelência, em que diferentes grupos populacionais exercem as suas ocupações laborais e os seus deveres e direitos, desenvolvem as suas actividades, exprimem os seus traços culturais e estilos de vida e reinventam as suas identidades e esta multiculturalidade alarga e diversifica o âmbito de acção do pluralismo na esfera do planeamento e gestão urbana e das políticas públicas. O espaço urbano proporciona uma rede complexa de inter relações e de vivências, uma diversidade de relações entre os indivíduos, os locais de residência, de trabalho, de lazer e distracção. Estas redes poderão favorecer uma progressiva integração das diferentes comunidades, promover a sua inserção num tecido social e cultural mais vasto, influenciando os seus valores, comportamentos, realizações e desenvolvendo atitudes de auto-confiança e emancipação, que conduzem ao aproveitamento de oportunidades emergentes e de acesso aos direitos. Com efeito, quanto maior for a diversidade de redes de relações sociais de um indivíduo, maior é o acesso às oportunidades de integração, de educação, de saúde e bem-estar e de mobilidade individual, social e familiar. Quando a oportunidade de residir em espaços possuindo recursos, infra-estruturas e equipamentos de qualidade estiver, igualmente distribuída entre os diferentes grupos populacionais, incluindo os migrantes e minorias étnicas, a capacidade de desenvolvimento pessoal, social e profissional e de comportamentos saudáveis poderá ser promovida e orientada no sentido da igualdade de oportunidades, da inclusão, da qualidade de vida e bem-estar de todos os cidadãos.

Importa acentuar que o acolhimento e integração dos migrantes nas sociedades receptoras, em particular na cidade, onde se concentram ao nível residencial e laboral, estão relacionados com um conjunto complexo e variado de factores, onde se destacam factores psicológicos, socioeconómicos, culturais e políticos, que reenviam ao próprio estatuto social, económico e jurídico do indivíduo migrante na sociedade de acolhimento, às suas redes sociais e de suporte às atitudes da sociedade de acolhimento e às políticas dos governos e dos Estados.

A migração constitui um desafio importante para os Estados, nomeadamente ao nível da ordem jurídica, a definição dos direitos dos trabalhadores migrantes e das suas famílias assumindo particular importância. É neste contexto que foi adoptada pela Assembleia Geral das Nações Unidas (Resolução no 45/158, de 18 de Dezembro de 1990) a "Convenção Internacional sobre a Protecção dos Direitos de Todos os Trabalhadores Migrantes e dos Membros das suas Famílias", a qual entrou em vigor em 2003.

Para o Comité Económico e Social Europeu (CESE, 2004), esta Convenção tem como objectivo: "A protecção dos direitos humanos e da dignidade das pesooas que emigram por razões económicas ou laborais em todo o mundo, mediante legislações adequadas e boas práticas nacionais". Segundo o CESE, a Convenção "reconhece a protecção internacional de determinados direitos humanos fundamentais, definidos na Declaração Universal dos Direitos do Homem, para todos os trabalhadores migrantes e suas famílias".

\section{Aculturação, Stresse e Doença}

A população imigrante é uma população heterogénea. Contudo, a predominância de baixos níveis de escolarização e de qualificação profissional, a inserção tendencial em sectores onde é mais precária e instável a relação salarial, onde há um mais baixo nível de remuneração global, onde há um grande peso de integração de migrantes em situação irregular, desprovidos de sistemas de protecção social, a precariedade da sua situação social e económica, fazem do grupo de imigrantes um grupo particularmente vulnerável, nomeadamente, ao nível da saúde. Também, as condições sociais e habitacionais precárias, o desenraizamento e isolamento social, as dificuldades em compreender e adoptar as normas sócio culturais da sociedade receptora e da vida urbana, o desconhecimento dos serviços existentes e dos direitos que lhes assistem, assim como, as atitudes de discriminação, vêm reforçar a exclusão social e cultural, reduzir as possibilidades de contactos sociais e de participação na vida colectiva, aumentar as dificuldades de recurso às estruturas de apoio e acentuar os factores de risco, de stresse e de vulnerabilidade (Ramos, 2004, 2008; Scheppers, Dongen, Dekker \& Geertzen, 2006; Stampino, 2007).

Os migrantes tendem, em geral, a concentrar-se por origem étnica, muitas vezes, em bairros ilegais ou zonas degradadas, com fracas condições de habitabilidade e higiene, em alojamentos sobrelotados, partilhando idênticas condições de vida e factores de precariedade e exclusão social. A homogeneidade das populações que residem em bairros e/ou habitações degradadas, e sobrelotadas, em termos de escolarização, de rendimento e muitas vezes de origem étnica, a concentração de populações que 
vivem em condições sócio - económicas precárias, com fracas redes sociais, instabilidade familiar e profissional, elevadas taxas de violência e delinquência, constituem elementos que agravam as dificuldades de integração na sociedade e que dificultam a formação de sociabilidades. Estes factores podem conduzir a situações de isolamento e ghetto, favorecendo a estigmatização e a emergência de tensões sociais e sentimentos de intolerância e discriminação da população autóctone, podendo provocar, ainda, distúrbios somáticos e psicopatológicos tanto nas crianças, como nos jovens e adultos (Kasl e Berkman,1983; Burke, 1984; Ramos, 1993, 2004, 2008; Taylor, Repetti \& Seeman, 1997).

Estes bairros e zonas degradadas são, em geral, marcados por um certo estigma e isolamento geográfico, social e simbólico, face ao resto da cidade onde, frequentemente, as crianças e os jovens, sobretudo das segundas e terceiras gerações de migrantes, acumulam insucesso escolar e problemas de adaptação social, desenvolvem atitudes anti-sociais, de violência e rejeição e organizamse em culturas e grupos de resistência, reproduzindo e aumentando as situações de exclusão social, de vulnerabilidade e de stresse.

O processo migratório, envolvendo rupturas espaciais e temporais, transformações diversas, nomeadamente mudanças psicológicas, ambientais, biológicas, sociais, culturais, familiares, políticas, implicando a adaptação psicológica e social dos indivíduos e das famílias e diferentes modalidades de aculturação, constitui um processo complexo, com consequências ao nível do desenvolvimento individual, sócio - profissional e da saúde física e psíquica.

A migração não implica apenas a deslocação espacial e não é, simplesmente, sinónimo de encontro cultural. Implica uma adaptação à cultura de acolhimento, a um meio novo, desconhecido ou hostil. Constitui um processo complexo, contraditório, uma experiência de perda, ruptura, mudança, vivenciada pelo indivíduo de uma forma mais ou menos traumatizante ou harmoniosa, segundo os seus recursos psicológicos e sociais, as características da sociedade dominante, as condições de acolhimento e as políticas do país receptor.

A experiência da migração envolve uma mudança psicossocial profunda semelhante a um luto ou a uma incapacidade estando, em geral, associada a stresse e sofrimento, mais ou menos significativos segundo os diferentes tipos de migração. Eisenbruch (1988) utiliza a expressão luto cultural, para designar a situação dos indivíduos que sofreram a perda traumática da terra mãe e da cultura de origem, aplicando-se esta designação, sobretudo a emigrantes involuntários, tais como, refugiados e exilados. As profundas mudanças pelas quais passam estes grupos assemelham-se pelo seu sofrimento colectivo, às de indivíduos enlutados e envolvem, igualmente, reacções de pesar e luto que podem ser patológicas e atípicas.

Viñar (1992) acentua a psicopatologia do exílio, sublinhando que o traumatismo, o sofrimento e o sentimento de perda, caracterizam o luto vivido pelo migrante e exilado na primeira fase migratória. Maisondieu (1997) fala de síndrome de exclusão para descrever o sofrimento psicológico e o desespero característico de muitos imigrantes e refugiados, sobretudo no período inicial, confrontados com a precariedade das condições de vida e com as mudanças de referências culturais. Trata-se de um sentimento de vergonha, desespero e impotência, face a uma situação dolorosa e stressante que o indivíduo não consegue controlar, que o afecta nas suas vivências e expectativas quanto ao futuro, nas suas relações, nas suas capacidades em exigir e defender os seus direitos, podendo associar-se a outros sintomas depressivos e pós-traumáticos.

Os migrantes são obrigados a fazer face ao isolamento, à solidão, à insegurança e à incompreensão, a abandonar a família, os amigos, os locais conhecidos e seguros para enfrentarem, não apenas uma nova cultura e língua, novos hábitos culturais, sociais e religiosos mas, muitas vezes, também a hostilidade, a discriminação, a insegurança e a indiferença da população, factores que vão influenciar na sua qualidade de vida e saúde física e mental, nomeadamente na depressão, tanto das crianças, como dos adultos (Franken, Coutinho \& Ramos, 2007; Coutinho, Franken \& Ramos, 2008). A migração implica, assim, a adaptação social e psicológica mas, também, a incorporação pelo indivíduo de uma cultura, língua, regras culturais e sociais diferentes, tendo o imigrante de desenvolver estratégias de adaptação que lhe permitem resolver as dificuldades relacionadas com a condição de imigrante e de aculturação.

Em contexto migratório, se é importante ter em conta o nível de integração e as reacções de adaptação dos migrantes às novas condições espaciais e sócio - culturais torna-se, igualmente, importante analisar as características da sociedade de acolhimento, nomeadamente, as condições sociais, económicas e políticas dominantes e factores como a xenofobia, a discriminação e o preconceito, os quais contribuem para o desencadear e manutenção da exclusão, do stresse psicológico e social e afectam o bem estar e a qualidade de vida (Burke, 1984; Scheppers, Dongen, Dekker \& Geertzen, 2006; Stampino, 2007).

Os acontecimentos significativos de vida, nomeadamente a migração podem constituir factores de stresse, 
na medida em que obrigam, em geral, a uma modificação de hábitos, de relações sociais, de padrões de actividade e de estilo de vida. A migração poderá, assim representar uma experiência traumática e dolorosa, capaz de originar traumatismos silenciosos e múltiplos e situações de elevado stresse.

A aculturação implica a aprendizagem de uma nova cultura, assim como escolhas por vezes difíceis entre o que o imigrante gostaria de manter e o que tem de abandonar dos hábitos e da cultura de origem. Dúvidas e ansiedade podem surgir, encontrando-se o indivíduo dividido entre o desejo de integrar os elementos da cultura do país de acolhimento e o desejo de manter tradições e hábitos de origem profundamente enraizados desde há longo tempo (Ramos, 1993). Este conflito devido à coexistência de dois códigos culturais, por vezes, contraditórios e incompreensíveis e à impossibilidade em estabelecer mediações entre dois universos diferentes, assim como, à incapacidade em lidar com as exigências do ambiente, poderão ter efeitos desorganizadores no comportamento e estarem na origem de distúrbios psicopatológicos, dificuldades de adaptação e stresse de aculturação.

Para Berry (1989, como citado em Ramos, 1993), o stresse social e psicológico devido à aculturação manifesta-se, nomeadamente, por problemas psíquicos (depressão, angústia, ansiedade, confusão), por problemas identitários, de marginalização, sentimentos de insegurança e perda de auto estima. Para este autor o stresse de aculturação poderá ser, mais ou menos importante, mas não é inevitável, sendo as relações entre aculturação e stresse influenciadas por um conjunto de factores, tais como: as características sócio demográficas e psicológicas do indivíduo, as particularidades da sociedade dominante, os tipos de aculturação e os modos de aculturação.

As características sócio demográficas do indivíduo, tais como a idade, o sexo, o nível sócio económico, o estatuto social, assim como, certas experiências, nomeadamente a miséria, a tortura, a exclusão, a xenofobia, podem influenciar o nível de stresse. Também as características psicológicas do indivíduo, nomeadamente as estratégias de adaptação (coping), o controlo, as motivações, as competências, a atitude face ao processo de aculturação, o sentido de identidade cultural, podem igualmente ter influências no nível de stresse.

Entre as comunidades de imigrantes e de minorias étnicas, certos traços culturais, tais como, o grau de coesão familiar e do grupo, o apoio/suporte social, as redes de solidariedade grupal, o sentimento de pertença identitária e os valores religiosos e espirituais, são ele- mentos protectores contra a doença mental e o stresse. Outros factores, tais como, o isolamento social, tabus e prescrições religiosas, desigualdades de género, conflitos intergeracionais, pressões familiares sobre os jovens para a obtenção de sucesso financeiro ou académico e condições habitacionais precárias e sobrelotadas, podem aumentar a tendência para a doença mental e psicopatologia nestes grupos e para a redução da qualidade de vida (Kiritz \& Moos, 1974).

Em relação às características das sociedades, Berry (1989) refere que a probabilidade de um nível de stresse elevado é maior nas sociedades monoculturais e assimilacionistas do que nas sociedades tolerantes e pluralistas. São os indivíduos que procuram a integração os que têm a taxa de stresse mais baixa. Por outro lado, é nos grupos marginalizados ou nos indivíduos que vivem situações de conflito nas suas tentativas de separação, que o nível de stresse é o mais elevado.

Eckenrode e Gore (1981) analisam o stresse em termos de acontecimentos de vida e redes de apoio existentes, destacando um conjunto de variáveis, tais como a saúde, a educação e o estatuto socioeconómico que determinam o impacto de um dado agente de stresse. Para estes, as redes sociais são uma forma privilegiada de compreender as origens da perturbação e o papel do apoio social, agindo este apoio como uma variável atenuante e preventiva do stresse e da doença. Com efeito, a saúde mental e física podem ser afectadas por factores sócio culturais e pela influência das redes sociais, constituindo o apoio e as relações sociais um importante protector de saúde, como salientam alguns estudos. Por exemplo, o isolamento social e a falta de redes sociais, estão relacionados com um maior índice de doença e mortalidade, como é evidenciado no estudo de grande dimensão realizado por Berkman e Syme (1979). Este estudo conhecido por "Alameda County" e que acompanhou os participantes durante nove anos, concluiu que os indivíduos com menos redes sociais e mais isolados, tanto homens como mulheres, sofrem um índice mais elevado de mortalidade, comparativamente com os indivíduos com mais laços sociais e menos isolados.

Outras investigações mostram que os acontecimentos de vida geradores de stresse estão excessivamente representados nas minorias e classes socioeconómicas mais baixas (Dohrenwend, 1973; Myers, Lindenthal \& Pepper, 1974) e a maior vulnerabilidade destas é também determinada pelo menor apoio social (Brown \& Harris, 1978; Adler, Boyce \& Chesney, 1994). A origem étnico/ cultural está frequentemente associada com a classe social, 
pertencendo uma proporção importante de migrantes e minorias étnicas ao estrato socioeconómico baixo, este estando relacionado com uma maior frequência de mortalidade, de morbilidade, de doenças graves, com mais comportamentos de risco para a saúde (álcool, tabaco, sedentarismo), com um nível mais elevado de stresse, com uma mais fraca integração social, com uma menor rede de suporte social e com uma mais baixa esperança de vida (Berkman \& Syme, 1979; Marmot Smith \& Stansfeld, 1991; Cohen \& Wills, 1985; Wilkinsen, 1992; Ramos, 1993, 2004, 2008; Wells et al. 2001; Lopes, 2008). Esta relação entre estrato socioeconómico e saúde/doença deve-se, não só às desigualdades de oportunidades mas, também, às diferenças que existem relativamente à exposição a agressões ambientais, aos estilos de vida, às condições habitacionais e laborais, às estratégias de adaptação social e controlo pessoal, ao suporte social, ao nível de stresse, ao acesso aos serviços de saúde e à distribuição da riqueza (Carroll, Bennett \& Davey Smith, 1993; Stronks, Ravelli \& Rejineyveld, 2001; Scheppers, Dongen, Dekker \& Geertzen, 2006; Stampino, 2007).

Constata-se que a saúde, mortalidade e doença grave e o acesso aos cuidados de saúde, variam de forma acentuada com as condições socioeconómicas nos diferentes países, tanto em homens como em mulheres, e muitos dos factores que aumentam a vulnerabilidade à doença nos grupos sociais mais desfavorecidos afectam, igualmente, muitos dos indivíduos migrantes e de minorias étnicas (Arber, 1989; Marmot, Smith \& Stansfeld,1991; Wilkinsen, 1992; Sousa, 2008; Lopes, 2008).

A pobreza, o desemprego, a privação e a exclusão, são importantes factores de stresse e doença em todas as comunidades (Parkes, 1971; Kiritz \& Moos, 1974; Goldberg \& Comstock, 1980; Robinson, 1984). Os estereótipos negativos, as relações desiguais entre grupos minoritários e maioritários, os discursos desvalorizantes e as atitudes discriminatórias em relação às minorias, por exemplo, em relação à cor da pele, constituem igualmente um factor de tensão, de stresse e de sofrimento acrescido (Shérif, 1970; Greenfield \& Cocking, 1994; Meyers, 1995).

Muitos imigrantes têm, frequentemente, menos oportunidades de se familiarizarem com a língua e a cultura da sociedade de acolhimento, ocupam empregos instáveis e mal remunerados, enfrentam conflitos entre os valores familiares e os valores da escola e do local de trabalho e dificuldades económicas, de habitação e isolamento familiar e social, o que vem acentuar as dificuldades psicológicas e aumentar o stresse. Para Rack (1982); Kessler e Neighbors (1986); Littlewood e Lipsedge (1989); Doyle (1991); Ramos (1993, 2004, 2005, 2006, 2008); Narang e Murphy (1994); Anderson (1995); Reijeneveld (1998); Scheppers, Dongen, Dekker e Geertzen (2006); Sousa (2008), para além destes factores, os migrantes e as minorias étnicas têm mais fontes de stresse e possibilidade de sofrer os efeitos dos factores ambientais de stresse devido à interacção complexa de variados factores: precariedade das condições de habitação e de trabalho; baixo rendimento familiar; discriminação e racismo; conflitos culturais e intergeracionais, sobretudo entre os imigrantes e os filhos nascidos no país de acolhimento; isolamento social; dificuldades comunicacionais e linguísticas, sobretudo no caso das mulheres, muitas vezes confinadas ao espaço familiar e doméstico; e, ainda, ao facto de possuírem menos recursos para enfrentar o stresse, à perda das referências básicas e às mudanças no espaço vital, nomeadamente a adaptação ao meio urbano e a novo estilo de vida. Os migrantes enfrentam, igualmente, mais limitações a serviços e bens que promovem a saúde e previnem a doença, apresentando mais dificuldades de acesso aos serviços, nomeadamente, de saúde recorrendo, por exemplo, menos aos cuidados pré-natais e aos rastreios de cancro do que os nacionais. Para Lazarus e Strohl (1995) os migrantes reúnem um número mais grave de patologias devido ao diagnóstico e tratamento tardios e à carência psicossocial, vindo as situações de isolamento, de clandestinidade e de discriminação agravar o problema.

A O.M.S. (1983) num estudo realizado na Holanda sobre a população migrante, evidencia que a pobreza das condições de vida, as condições de trabalho e habitação geralmente precárias, os hábitos alimentares, os problemas culturais e comunicacionais, o acesso inadequado aos cuidados de saúde, a ansiedade, a depressão e as dificuldades de integração, constituem para os migrantes factores que influenciam a saúde física e psíquica.

Por seu lado, um inquérito realizado pelo CREDES, em 1998, em França, junto de pessoas que recorriam aos centros de cuidados gratuitos da região parisiense, constatou uma predominância de utentes de nacionalidade estrangeira (68 a 84\%, segundo os centros). Comparativamente com a população geral atendida, esta população apresentava as seguintes características: um pior estado de saúde geral; uma frequência mais elevada de certas patologias, nomeadamente, dores, síndromes depressivos e intoxicações; um recurso elevado ao hospital público, contrariamente ao recurso ao privado, o qual era raro. Também as situações de renúncia aos cuidados são duas vezes mais frequentes nos migrantes do que na população 
geral: $65 \%$ dos utentes/doentes estrangeiros declararam ter abandonado os cuidados curativos ou os medicamentos (CREDES, 2003).

\section{Migração, Maternidade e Saúde}

Ser mãe em situação de migração poderá representar um risco, um trauma e uma fonte de stresse e depressão para a mãe, com consequências para a criança, devido às rupturas, ao isolamento, solidão, dúvidas e ansiedade que acompanham esta etapa. Com efeito, são particularmente as mães e as crianças, sobretudo nos primeiros anos de vida, as mais vulneráveis ao stresse, às rupturas, às transformações e às dificuldades resultantes do processo migratório (Ramos, 1993, 2004, 2008, 2009).

Também, muitas mães migrantes são obrigadas a deixarem os seus filhos no país de origem ao cuidado de outros familiares para cuidarem de outros (crianças e idosos) nos países de acolhimento, o que alguns autores designam de "maternagem transnacional" (HondageuSotello \& Ávila, 1997) e de "cadeias globais de assistência" (Hochschild, 2000), esta situação tendo implicações psicológicas, familiares e sociais importantes, particularmente, para as mães e as crianças.

Em contexto migratório, o nascimento, momento de ruptura do envelope materno - psíquico e físico reactiva, em geral, o sofrimento e a dor do exílio e da separação. A migração vem complicar e vulnerabilizar a situação de gravidez e maternidade e as primeiras interacções com a criança pelos condicionalismos impostos pela migração: a aculturação, a solidão/isolamento e o individualismo.

$\mathrm{O}$ nascimento em situação migratória favorece e acentua distúrbios culturais e psicológicos que são, também, verificados nas mulheres autóctones das sociedades ocidentais, distúrbios fortemente ligados ao isolamento e solidão das mães e à cultura do individualismo, valor fundamental da sociedade actual. Para as mães migrantes, esta situação constitui um drama e é fonte de sofrimento, sobretudo para as que vêm de meios tradicionais, onde a mãe e a criança são fonte de cuidados de toda a família e da comunidade envolvente.

Tradicionalmente a gravidez constitui um processo iniciático onde a futura mãe tem o apoio e acompanhamento das mulheres da família e do grupo. A migração origina numerosas rupturas neste processo de partilha e de construção de sentido: perda de acompanhamento pelo grupo, falta de suporte familiar, social e cultural e impossibilidade em dar um sentido culturalmente aceitável a disfuncionamentos, tais como a tristeza e sofrimento da mãe, o sentimento de incapacidade, as interacções mãe - criança desarmoniosas. Em contexto migratório a família separa-se da vida comunitária tradicional, reduz-se a uma família nuclear, a qual deverá assegurar sozinha as responsabilidades partilhadas até aqui pela família alargada e comunidade. A perda dos laços comunitários e familiares significa a perda da protecção física, psicológica e da tradição. Quando a cultura, o grupo desaparece como fonte de transmissão, nomeadamente ao nível das práticas de maternagem, as competências da mãe são fortemente solicitadas, tendo esta de fazer face às exigências da sociedade em ser, não só uma boa mãe, como ao choque cultural, à adaptação ao novo meio e ao trabalho de luto. Para algumas mulheres dar à luz, longe da cultura materna, da família, sobretudo para as que vêm de sociedades onde estes elementos são fundamentais na transmissão, este luto e afastamento provoca conflitos no papel materno, devido ao desequilíbrio entre as representações maternas e a realidade vivenciada (Ramos, 1993, 2008, 2009).

$\mathrm{Na}$ nova sociedade, exigências culturais contraditórias ou incompreensíveis podem conduzir a família, nomeadamente a mãe, a ter dificuldades em decidir sobre os comportamentos a adoptar em relação ao modo de lidar com os seus filhos, à incapacidade de agir em caso de mau estar ou de doença. A mãe migrante, transplantada de uma cultura para outra, isolada, desenraizada corre o risco de não saber com a mesma segurança quais os gestos e os comportamentos a adoptar, pois as referências não são as mesmas e o sistema referencial vacila. A situação de conflito cultural, a insegurança e ansiedade daí resultantes estão na origem de "conflitos maternos" muito prejudiciais para a relação mãe/criança e para as interacções familiares (Stork, 1986; Ramos, 1993, 2004, 2008, 2009). Algumas mães em situação de "desaculturação", isoladas, desenraizadas, deprimidas, faltando-lhes referências tradicionais sobre as quais se apoiarem, por vezes, mães muito jovens, não encontram nelas mesmas, nem no meio familiar e social, os recursos necessários para se adaptarem a um novo meio e cultura e para cuidarem dos seus filhos. Verificamos neste grupo uma maior vulnerabilidade da mãe e da criança, mais situações de risco, mais depressões e psicoses, nomeadamente pós parto, mais distúrbios psicossomáticos, tais como vómitos na gravidez, insónias, sobretudo nas primíparas, menor vigilância pré-natal, mais problemas de identidade, assim como, mais distúrbios funcionais do bebé, nomeadamente problemas de sono e alimentação.

Os estudos sobre a saúde das mulheres migrantes, nomeadamente, na União Europeia, na América do Norte, na América Latina e na Ásia registam, sobretu- 
do, problemas de saúde reprodutiva, apontando piores indicadores de saúde associados a esta população. As mulheres migrantes têm poucos conhecimentos sobre os serviços sociais e de saúde, utilizam, em geral, menos frequentemente os serviços de saúde reprodutiva do que as mulheres não migrantes, com frequência não recebem cuidados pré-natais ou recebem este tipo de cuidados de modo inadequado ou tardio, apresentam uma menor utilização de métodos contraceptivos e maior vulnerabilidade às doenças sexualmente transmissíveis, registam mais gravidezes indesejadas, taxas mais elevadas de aborto espontâneo, de recém-nascidos com baixo peso e de mortalidade perinatal e infantil (Ramos, 1993, 2004, 2008, 2009; Bollini \& Siem, 1995; Essen, Hanson \& Ostergren, 2000; Thorp, 2003; Mosher, Martinez, Chandra, Abma, \& Willson, 2004; Machado, Santana, Carreiro, Nogueira, Barroso \& Dias, 2006; Lopes, 2008, Manuel, 2008; Bragg, 2008).

Importa salientar que a gravidez, o parto e os primeiros cuidados à criança são, ainda, nas sociedades tradicionais, de onde são originárias muitas mulheres migrantes, rodeados de um conjunto de práticas e rituais que passam de geração em geração e onde a figura materna e a comunidade envolvente desempenham um papel fundamental no nascimento e nos cuidados à mãe e à criança. No ocidente a solidão e o isolamento acompanham o nascimento, assim como a valorização da interioridade e do individualismo e a solicitação de ser uma boa mãe, com as implicações de responsabilidade, mas também de exigência e culpabilidade.

Em especial em situação de migração, existe um conjunto de rituais em torno da gravidez, do parto e do recém-nascido que se rompe e que desempenhava um papel protector e uma função psicológica importante. $\mathrm{O}$ universo anónimo, isolado, tecnológico e estranho das instituições de saúde e práticas médicas consideradas pelas mães, violentas, traumatizantes e impúdicas não respeitando modos de protecção tradicionais vêm aumentar a vulnerabilidade destas mães, reforçar a situação de isolamento, de stresse e de angústia para a mulher oriunda de outro universo cultural. Esta, sobretudo aquela que é mãe pela primeira vez, vive com medo, ansiedade e muito stresse este período, devido ao isolamento e às grandes diferenças entre o meio cultural, familiar e protector de origem e o universo anónimo, distante, tecnológico e incompreensível com o qual se vê confrontada. Esta situação "estranha", de stresse e vulnerabilidade tem consequências prejudiciais para a saúde da mãe e do bebé, na comunicação com os profissionais de saúde, na adesão e utilização dos serviços de saúde pela mulher, nomeadamente, migrante e desencadeia, muitas vezes, nos profissionais de saúde comportamentos inadequados e agressivos, atitudes de rejeição e problemas de comunicação e de diagnóstico (Ramos, 1993, 2004, 2008, 2009; Bulman \& McCourt, 2002; Kennedy \& Murphy-Lawless, 2001; Cuadrado, Avalos, Sanchez, Fernandez, Alonso \& Bértolo, 2004).

Torna-se importante intervir ao nível da prevenção perinatal, escutar as mães e ajudá-las a investirem nos seus bebés, sendo necessário também aprender a reconhecer o sofrimento e as dificuldades das mães migrantes, através, nomeadamente das queixas somáticas, preocupações em relação à criança, pedidos de ajuda social. É importante, também, favorecer a partilha das suas vivências com outras mães na mesma situação e permitir-lhes comunicar na sua língua, quando necessário, por intermédio de outras mulheres que partilham a mesma língua.

\section{Considerações Finais}

A pluralidade e a heterogeneidade dos mundos contemporâneos exigem aprender a viver e a respeitar a multiplicidade de pertenças e de referências, não sob a forma de dicotomias, de exclusividade e de exclusão, mas de um modo plural, contínuo e complementar.

O processo da interculturalidade vem contribuir para o fortalecimento da coesão social, da cidadania e da construção de uma sociedade plural e intercultural, bem como para a promoção do desenvolvimento, da saúde, da alteridade, das identidades e pertenças culturais e da comunicação intercultural entre indivíduos, grupos e nações. (Clanet, 1990; Sandercock, 2004; Ramos, 2001, 2003, 2005, 2006, 2007, 2008).

Para Sandercock (2004), o diálogo intercultural tem de estar presente no quotidiano e assente em dois tipos de direitos fundamentais: o "direito à cidade", enquanto espaço colectivo, promotor da participação e integração de todos na construção da cidade; o "direito à diferença", enquanto promoção e valorização da diversidade cultural, da comunicação intercultural e da alteridade. A problemática das migrações e da diversidade cultural vem colocar muitos desafios à sociedade, ao Estado e às políticas do século XXI nos diversos sectores, particularmente na saúde, implicando um novo reposicionamento metodológico, epistemológico e político ao nível da teoria, pesquisa e intervenção.

A crescente multiculturalidade que se verifica nos diferentes contextos da vida pública exige esforços na reformulação de estratégias e políticas públicas com o 
objectivo de melhorar a saúde, a qualidade de vida, o acesso aos serviços públicos e a comunicação entre os diferentes grupos que coabitam no mesmo espaço.

É necessário proporcionar ao indivíduo migrante um enquadramento psicossocial, familiar, cultural, sanitário e jurídico, capaz de transformar o risco, o trauma, a ruptura que comporta a situação migratória, num processo estruturante, capaz de transformar a vulnerabilidade, a exclusão, a patologia, frequentemente associados à migração, num processo dinamizador, criativo e inclusivo.

É importante a adopção de modelos explicativos sistémicos, multifactoriais e holísticos, já que só uma abordagem multi/interdisciplinar, multidimensional, interaccionista e ecológico-cultural permitirá ter em conta a globalidade e a complexidade dos processos e factores que intervêm nas relações de saúde e doença, na diversidade das experiências de adaptação e das vivências psicológicas, culturais e sociais dos indivíduos e dos grupos e, ainda, na integração social e na adesão aos cuidados de saúde.

É indispensável implementar estratégias e políticas baseadas numa perspectiva de equidade e solidariedade e em políticas sociais, sanitárias e educativas coordenadas e adaptadas às características e necessidades dos diversos grupos étnico-culturais. Deste modo, as políticas sociais e os cuidados de saúde ao nível local, nacional e internacional, têm de ser humanizados e sensíveis às necessidades e aspirações dos indivíduos, dos grupos e das comunidades e culturalmente competentes.

Uma sociedade multi/intercultural e um mundo globalmente interdependente necessitam de uma nova abordagem de cidadania para as populações autóctones e migrantes, que incorpore a dinâmica da mudança, da diversidade cultural e os princípios fundamentais dos direitos humanos, em estratégias e políticas que promovam o desenvolvimento humano, a inclusão, a igualdade de oportunidades e o pleno aceso à cidadania.

As problemáticas sociais, culturais e sanitárias decorrentes das migrações, exigem novos modelos conceptuais e novas políticas e estratégias de intervenção, capazes de gerir a diversidade cultural e de promover e harmonizar os direitos humanos e culturais, com as necessidades, qualidade de vida e bem-estar dos indivíduos, das famílias e dos grupos, maioritários ou minoritários, nacionais ou migrantes. Como estipula a Conferência das Nações Unidas do Cairo sobre População e Desenvolvimento (ONU, 1994), no seu artigo 12: "Os países deverão garantir a todos os migrantes os direitos humanos fundamentais integrados na Declaração Universal dos Direitos Humanos".

\section{Referências}

Adler, N., Boyce, T., \& Chesney, M. (1994). Socioeconomic status and health: the challenge of the gradient. American Psychologist, 49, $15-24$.

Anderson, N. (1995). Summary of task group recommendations. Health Psychology, 14 (7), 649-653.

Arber, S. (1989). Gender and class inequalities in health: understanding the differentials. In J. Fox (ed.) Health inequalities in european countries. Aldershot: Gower Publishing Company.

Berkman, L.,\& Syme, S. (1979). Social networks, host resistance and mortality: a nine -year follow-up study of Alameda County residents. American Journal of Epidemiology, 109, 186-204.

Berry, J. (1989). Acculturation et adaptation psychologique. La Recherche psychologique.I. J. Retschitzky, M. Bossel - Lagos, P. Dasen. (cord. Paris: L'Harmattan, 135-145.

Bollini, P., Siem, H. (1995). No real progress towards equity:health of migrants and ethnic minorities on the eve of the year 2000. Social Science \& Medicine, 41 (6), 819-828.

Bragg, R. (2008). Maternal deaths and vulnerable migrants. Lancet (371, 9616), 879-881

Brown, G., Harris, T. (1978). Social origins of depression: a study of psychiatric disorder in women. New York: Free Press.

Bulman, K.,\& McCourt, C. (2002). Somali refugee women's experience of maternity care in west London: a case study. Critical Public Health, (12, 4), 365-380

Burke, A. (1984). Racism and psychological disturbance among west Indians in Britain. Inst. J. Soc. Psychiatry, 30, 50-68.

Carroll, D., Bennett P., Davey Smith, G. (1993). Health and social material circumstances: their origins and implications. Psychology and health, 8 , 295-316.

CESE (2004). Parecer do Comité Económico e Social Europeu sobre a "Convenção Internacional para os Trabalhadores Migrantes" (JO n ${ }^{\circ} \mathrm{C} 302$, de 7 de Dezembro/2004.

Clanet, C. (1990). L'interculturel. Introduction aux approaches interculturelles en education et en sciences humaines. Toulouse: Presses Universitaire du Mirail.

Cohen, S., Wills, T. (1985). Stress, social suport and the buffering hypothesis. Psychological Bulletin, 109, 5-24.

Coutinho, M. P.L., Franken, I., \& Ramos, N. (2008). Depressão, Migração e Representações Sociaos no Contexto Escolar de Portugal. N. Ramos (org.). Saúde, Migração e Interculturalidade. João Pessoa : EDUFPB, 133-175.

CREDES (2003). Logique de recours aux soins des personnes en situation de precarité. Questions d'économie de la santé. Paris, 63.

Cuadrado, S., Ávalos, N., Sanchez, A., Fernandez, Y., Alonso, C., Bértolo, J. (2004). Características de las mujeres inmigrantes y de sus hijos recién nacidos. Anales de Pediatria, (60, 1), 3-8.

Dohrenwend, B. (1973). Social status and stressful life events. Journal of personality and social psychology, 28, 225-235.

Doyle, Y. (1991). Survey of the cervical screening service in a London district, including reasons for non attendance ethnic responses and views on the quality of the service. Social Science and Medicine, 32, 953- 957.

Eckenrode, J., \& Gore, S. (1981). Stressful event and social supports. The signifiance of context. In B. Gotthieb (ed.) Social networks and social support. Beverely Hills: Sage.

Eisenbruch, M. (1988). The mental health of refugee children and their cultural development. International Migration Review, 22, 282-300.

Essen, B., Hanson, B., \& Ostergren, P. (2000). Increased perinatal mortality among sub-Saharan immigrants in a city-population in Sweden. Acta Obstetricia Gynecologica Scandinavica (79), 737-742.

Franken, I; Coutinho, M., \& Ramos, N. (2007). Migração e qualidade de vida, o pensamento social de brasileiros migrantes. Krutzen, E.C., e Vieira,S.B.(org). Psicologia social, clínica e saúde mental. João Pessoa: Editora Universitária/UFPB.

Greenfield, P., \& Cocking, R. (1994). Cross cultural roots of minority child development. Hillsdale: Erlbaum.

Goldberg, E., \& Comstock, G. (1980). Epidemiology of life events: frequency in general populations. American Journal of epidemiology, 111, 736- 752 . 
Hochschild, A. (2000). Global care chains and emotional surplus value. W. Hutton, A. Giddens (Eds). On the edge: living with global capitalism. New York: Free Press.

Hondangneu-Sotelo, P., \& Avila, E. (1997). "I'm here but I'm there". The meanings of Latina transnational motherhood. Gender and society, 11 (5), 548-571.

Kasl, S., Berkman, L. (1983). Health consequences of migration. Annual Review of Public Health, 4, 69-90.

Kennedy, P., \& Murphy-Lawless, J. (2002). The maternity care needs of refugee and Asylum seeking women: A research study conducted for the women's Health Unit, Northern area health board. Dublin: Eastern Regional Health Authority.

Kessler, E., \& Neighbors, H. (1979). A new perspective on the relationships among race, social class and psychological distress. Journal of health and social behaviour. (27), 107-115.

Kiritz, S., \& Moos, R. (1974). Physiological effects on social environments. Psychosomatic Medicine, 36, 96-113.

Kleit, R. (2001). The role neighborhood social networks in scattered-site public housing residents'search for jobs. Hounsing Policy Debate, 12 (3), 541-573.

Lafond, J., Heritage, Z., Farrington, A., \& Tsouros, A. (2003). WHO - Europe national healthy cities networks. A powerful force for health and sustainable development in Europe. WHO: Copenhaga

Lazarus, A., Strohl, H. (1995). Une souffrance qu'on ne peut plus cacher. Ministère des Affaires Sociales, de la Santé et de la Ville : Rapport IGAS (1995161).

Littlewood, R., \& Lipsedge, M. (1989). Aliens and alienist. Unwin Wyman, 83-103.

Lopes, L. C. (2008). Gravidez em contexto de seropositividade num grupo de migrantes da região de Lisboa. N. Ramos (org.). Saúde, Migração e Interculturalidade. João Pessoa: EDUFPB, 311-347.

Machado, M., Santana, P., Carreiro, M., Nogueira, H., Barroso, M., \& Dias, A. (2006). Iguais ou diferentes? Cuidados de saúde materno-infantil a uma população de imigrantes. Lisboa: Bial.

Maisondieu, J. (1997). La fabrique des exclus. Paris : Bayard.

Manuel, H.I.B. (2008). Mulheres Timorenses em Portugal : Representações e práticas sobre planeamento familiar. N. Ramos (org.). Saúde, Migração e Interculturalidade. João Pessoa: EDUFPB, 261-310.

Marmot, M., Smith, G., \& Stansfeld, S. (1991). Health inequalities amoug british civil servants : the Whitehall II study. The Lancet, 337, 1387-1392.

Meyers, R. (1995). Relating health and nutrition to social and psychological development. In The twelve who survive: Strengthening programmes of early childhood development in the third world. Ypsilanti, Michigan: High/Scope Press.

Mosher, W., Martinez, G., Chandra, A., Abma, J., \& Willson, S. (2004). Use of contraception and use of family planning services in the United States: 1982-2002. Advance Data. (350), 1-36.

Myers, J., Lindenthal, J.,\& Pepper, M. (1974). Social class, life events and psychiatric symptoms: a longitudinal study. In B. Dohrenwend \& P. Dohrenwend (eds.). Stressful life events: their nature and effects. New York: John Wiley.

Narang, I., Murphy, S. (1994). An assessment of ante-natal care for asian women. British Journal of Midwifery, 2, 169-174.

OCDE (2007). Perspectives des migrations internationales. Paris: SOPEMI.

OMS (1983). Migration and health: towards and undestanding of health care needs ethnics minorities. Netherlands: Ed. M. Colledge.

ONU (1994). Programa de Acção da Conferência Mundial sobre População e Desenvolvimento. ONU: Cairo.

Parkes, C. (1971). Psycho-social transitions: a field for study. Social Science Medicine. 5, 101-115

Rack, P. (1982). Migration and mental illness: a review of recent research in Britain. Transcultural Research Review, 19, 151-172.

Ramos, N. (1993). Maternage en milieu portugais autochtone et im $\neg$ migré. De la tradition à la modernité. Une étude ethnopsychologi $\neg$ que. Tese de Doutoramento em Psicologia. Paris V: Universidade René Descartes, Sorbonne, vol I e II, $736 \mathrm{p}$.

Ramos, N. (2001). Comunicação, cultura e interculturalidade : Para uma comunicação intercultural. Revista Portuguesa de Pedagogia. (35, 2), 155-178.
Ramos, N. (2003). Interculturalité, communication et education. Bucareste: Ed. Melina Press.

Ramos, N. (2004). Psicologia Clínica e da Saúde. Lisboa: Universidade Aberta.

Ramos, N. (2005). Famílias e crianças em contexto de pobreza e exclusão - do desenvolvimento à saúde e à educação. Psychologica. 38, 241-263.

Ramos, N. (2006). Migração, aculturação, stresse e saúde. Perspectivas de investigação e de intervenção. Psychologica. 41, 329-350.

Ramos, N. (2006). Saúde, desenvolvimento e direitos humanos. Interface. $(3,1), 11-31$

Ramos, N. (2007). Comunicação e Interculturalidade nos Cuidados de Saúde. Psychologica. 45, 147-169.

Ramos, N. (org.). (2008). Saúde, Migração e Interculturalidade. João Pessoa: EDUFPB.

Ramos, N. (2008). A diversidade cultural na cidade: Problemas e Desafios. In L. Rubim e N. Miranda (orgs.). Transversalidades da Cultura. Salvador: EDUFBA, 133- 179.

Ramos, N. (2008). Cultura e desenvolvimento - Da saúde aos direitos humanos. A. Rubim, N. Ramos (org). Estudos da cultura no Brasil e em Portugal. Salvador: EDUFBA.

Ramos, N. (2009). "Mulheres portuguesas na diáspora - Maternidade, aculturação e saúde". L. Seabra, A. Espadinha (orgs). A vez e a voz da mulher portuguesa na diáspora - Macau e outros lugares. Macau: Universidade de Macau, $163-188$.

Reijneveld, S. (1998). Reported health, lifestyles and use of health care of first generation immigrants in the Netherlands: do socioeconomic factors explain their adverse position? Journal of Epidemiology and Community Health, 52 (5), 298-304

Robinson, R. (1984). Racial inequality and the probability of occupation - related injury or illness. Milbauk Memorial Fund Quarterly. (62), 567-590.

Rykwert, J. (1988). Preface to the Paper Edition. The Idea of a Town. MitPress.

Sandercock, L. (2004). Reconsidering multiculturalism: towards an intercultural project. Ph. Wood (ed.) Intercultural city reader (I). Bournes Green: Comedia.

Stampino, V. (2007). Improving access to multilingual health information for newcomers to Canada. Journal of the Canadian Health Libraries Association. (28), 15-18.

Scheppers, E., Dongen, E., Dekker, J., \& Geertzen, J. (2006). Potencial barriers to the use of health services among ethnic minorities: a review. Family Practice, (23,3), 325-348.

Sherif, M. (1970). Group conflict and co-operation: their social psychology London: Routeledge \& Kegan Paul.

Stork, H. (1986). Enfances indiennes. Étude de psychologie transculturelle et comparée du jeune enfant. Paris: Le Centurion.

Stronks, K., Ravelli, C., \& Reijneveld, A. (2001). Immigrants in the Netherlands: Equal access for equal needs? Journal of Epidemiology and Community Health. $(55,10), 701-707$.

Sousa, J. E. (2008). Imigrantes ucranianos em Portugale os cuidados de saúde. N. Ramos (org.). (2008). Saúde, Migração e Interculturalidade. João Pessoa: EDUFPB, 213-259.

Taylor, S., Repetti, R., \& Seeman, T. (1997). Health Psychology: What is an unhealth environment and how does it get under the skin? Annuel Review of Psychology. 48, 411-447.

Thorp, S. (2003). Born Equal. Health Development Today. (18), 21-23.

Viñar, M. e M. (1992). Exílio e Tortura. S. Paulo: Ed. Escuta.

Wilkinson, M. (1992). Income distribution and life expectancy. British Medical Journal. 304, 165-168.

WHO/EURO/HCPO (1988). Promoting health in au urbancontext. WHO Healthy Cities Papers. 1. FADL: Copenhaga.

WHO (1996). World health day : Healthy cities for better life. World Health Day. Genebra.

Enviado em 23/3/2010

Aprovado para publicação em 5/5/2010 